\title{
Motivação e Recompensas: uma investigação com base nas Teorias da Hierarquia das Necessidades e da Expectativa
}

\author{
Larissa Carvalho Alves ${ }^{1}$, Adriano Victor Lopes da Silva ${ }^{2}$, Erika Maria Jamir de Oliveira ${ }^{3}$
}

Resumo: Resumo: Este estudo objetivou identificar o tipo de recompensa que mais motiva o colaborador na Unimed Vale do São Francisco- Operadora, e se essa preferência independe do nível hierárquico a qual o colaborador está situado. A pesquisa possui caráter descritivo e critério misto, qualitativo e quantitativo. A técnica foi o estudo de caso, e a amostra foi a aleatória simples, composta por 55 colaboradores dos níveis tático e operacional, os participantes foram sorteados no software R 3.3.0. Os dados foram coletados por meio de entrevista, instrumentalizado por um formulário. Para verificação da independência ou associação entre a recompensa e o nível hierárquico foi utilizado o teste não paramétrico Qui- quadrado. Constatou-se que os colaboradores desejam ser estimulados através de recompensas financeiras e não financeiras, bem como que a escolha do tipo de recompensa independe do nível hierárquico.

Descritores: Motivação, Recompensas, Teoria da hierarquia de necessidades, Teoria da Expectativa.

\section{Motivation and Rewards: an investigation based on the Theories of the Hierarchy of Needs and Expectation}

\begin{abstract}
This study aimed to identify the type of reward that motivates the most the employee of the Unimed Vale do São Francisco - Operadora, and if this preference does not depend on the hierarchical level in which the employee is located. The research has descriptive character and mixed, qualitative and quantitative criteria. The technique was the case study, and simple random was the sample used, composed by 55 employees from the tactical and operational levels, the participants were drawn in the R 3.3.0. The data has been collected through an interview, by means of a form. In order to check the independence or the association between the reward and the hierarchical level the non-parametric chi-square test was used. It was verified that the employees want to be stimulated through financial and non financial rewards, as well as the choice of the reward type is independent to the hierarchical level.
\end{abstract}

Descriptors: Motivation. Financial reward. Non-financial reward.

\section{Introdução}

Em um mundo competitivo em que os consumidores estão cada vez mais exigentes, as empresas devem delinear estratégias para atrair, satisfazer e fidelizar o cliente com o intuito de manter-se e expandir-se no mercado. Nesse sentido, os gestores precisam perceber que para atender e superar os anseios dos clientes externos, será necessário satisfazer os seus clientes internos.

\footnotetext{
1 Bacharel em Administração de Empresas; Faculdade de Ciências Aplicadas e Sociais de Petrolina - FACAPE: Contato: larycarvalhoalves@hotmail.com;

${ }^{2}$ Universidade Federal do Vale do São Francisco. Contato: adriano.victor@univasf.edu.br;

${ }^{3}$ Docente na Universidade Federal do Vale do São Francisco - UNIVALE. Contato: erikamariajamirdeoliveira@gmail.com
} 
Segundo Birck e Gomes (2013) as organizações estão fragmentando a forma de investimento, além de investir na qualidade dos produtos e serviços, estão buscando o aprimoramento do capital humano, tendo em vista que os colaboradores são um dos principais componentes da empresa, pois são eles que prestam o atendimento ao cliente $\mathrm{e}$ consequentemente, a depender do atendimento, conquistam a fidelização do consumidor.

Para isso, o gestor pode fazer uso das teorias sobre a motivação humana, conhecer o papel de cada colaborador -considerando o seu nível hierárquico-, para que sejam designadas atribuições e recompensas eficazes. Existem basicamente três níveis hierárquicos: estratégico, tático e operacional. No nível estratégico toma-se decisões sobre todo o ambiente organizacional (interno e externo), projetados no longo prazo; no tático realiza-se o desdobramento e a implantação das decisões do planejamento estratégico; no nível operacional executa-se as tarefas atribuídas pelo nível tático, efetuada em curto prazo a produção de bens ou serviços (CHIAVENATO, 2014). Nesta pesquisa, levou-se em consideração a possibilidade de que colaboradores em níveis hierárquicos diferentes, pudessem ter necessidades, desejos e valores diferentes.

A motivação pode ser definida como uma influência de forças interiores do indivíduo, responsável por determinar o caminho que será seguido para alcançar o propósito estabelecido e o nível da perseverança diante das dificuldades (JONES; GEORGE, 2008). Segundo Robbins; Judge; Sobral (2010) faz-se necessário considerar a intensidade, direção e persistência.

Foi na década de 1950, que os estudos relacionados à motivação humana ganharam força, surgindo assim, as Teorias Clássicas sobre motivação humana, no qual os estudos caracterizavam-se pela determinação das formas de motivar o colaborador em uma organização. Porém, no decorrer do tempo, as Teorias Clássicas ficaram ultrapassas, e constatou-se a necessidade de pesquisas mais detalhadas, surgindo as Teorias Contemporâneas (ROBBINS; JUDGE; SOBRAL, 2010). Para este estudo, foi utilizada a Teoria Clássica da Hierarquia das Necessidades e a Teoria Contemporânea da Expectativa, com o intuito de verificar as semelhanças e diferenças na maneira de abordar a motivação do colaborador, entre as teorias de períodos distintos.

A primeira teoria elaborada sobre motivação foi a da Hierarquia das Necessidades, esta teoria determina que a motivação das pessoas está ligada primeiramente as necessidades 
externas (fisiológica e segurança), e posteriormente, as internas (social, estima e autorrealização), como pode ser vista na Figura 1.

Figura 1- Hierarquia das Necessidades de Maslow.

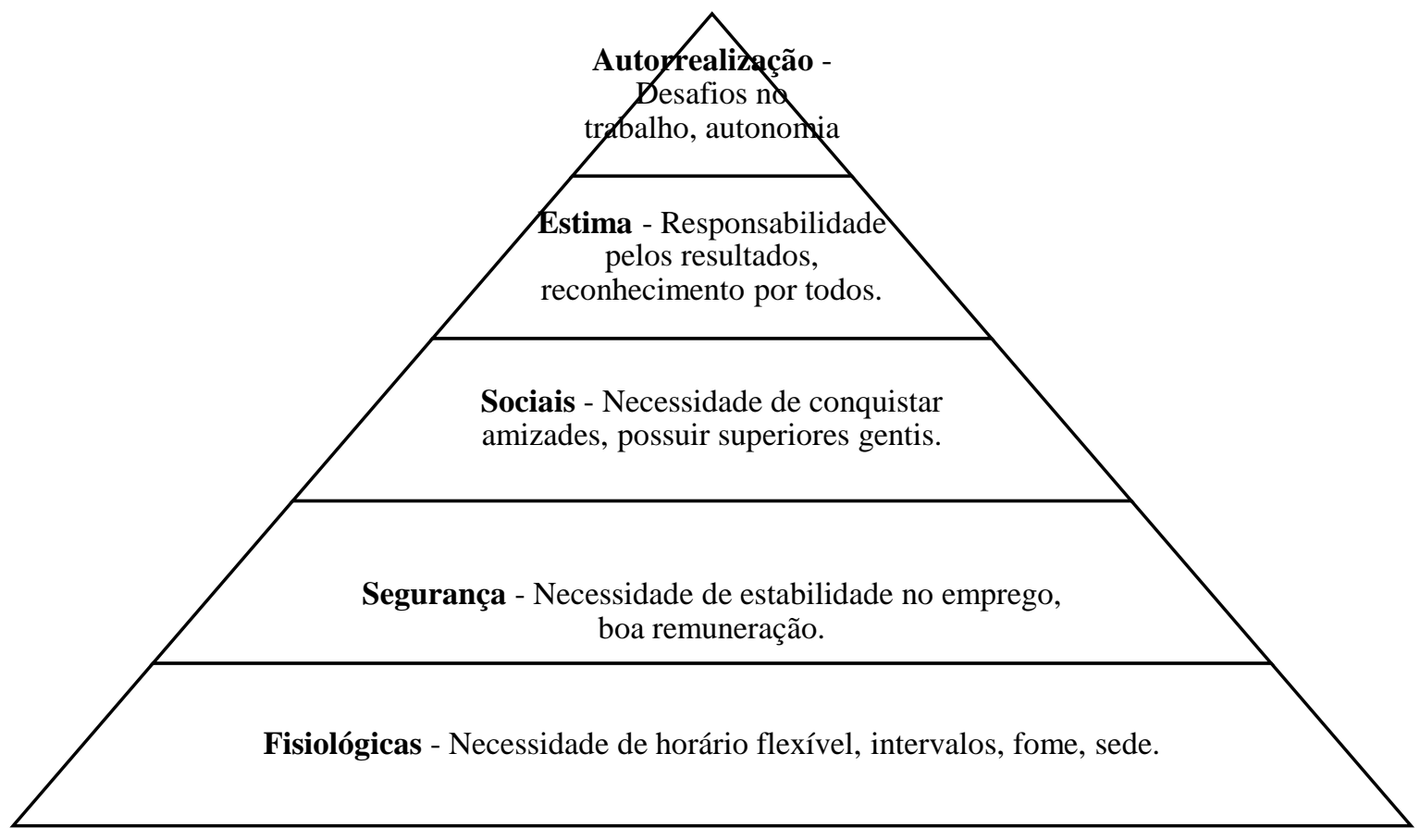

Esta Teoria foi criada com base nas experiências obtidas através dos procedimentos realizados com algumas pessoas em diversos estados de normalidade psicológica. Por meio desses estudos, o autor desta teoria estabeleceu cinco etapas diferentes de necessidades: fisiológica, segurança, social, estima e autorrealização (WAGNER E HOLLENBECK, 2012). Todas as necessidades estão associadas a algo do meio externo, exceto a etapa do topo da pirâmide, a autorrealização, no qual as pessoas que chegam a essa etapa sentem- se emancipados, não levam em consideração bens físicos, e sim, o regozijo interior (ROBBINS, JUDGE, SOBRAL, 2010).

A segunda teoria utilizada neste estudo foi a Teoria da Expectativa. Seguindo os preceitos de Jones e George (2008) esta teoria é uma das mais vinculadas ao ambiente de trabalho, em que evidencia três fatores: o esforço, desempenho e consequência, em que estabelecem a motivação do colaborador através de: o efeito de perceber de um funcionário as 
condições do desempenho (expectativa), a percepção que o desempenho está relacionado com as retribuições almejadas (instrumentalidade) e as escolhas das recompensas (valência).

Conforme Robbins, Judge e Sobral (2010) a teoria da expectativa possui três etapas, no qual o colaborador para alcançar os objetivos será essencial ter o conhecimento que, se o mesmo se esforçar para a realização das atividades profissionais terá o desempenho reconhecido. Posteriormente, confiar que o desempenho trará uma boa recompensa e por fim, que está recompensa seja de interesse próprio (metas pessoais), isto é, que a recompensa recebida supra as necessidades naquele momento, como pode ser visto na Figura 2. Por exemplo, tem- se um colaborador, onde o mesmo recebeu a notícia que a empresa proporciona uma recompensa ao funcionário que conseguir uma política de reduções de papéis. O desempenho do funcionário na execução dessa política dependerá do tipo de recompensa oferecida pela organização e se esta recompensa atenderá as necessidades do indivíduo na situação em que ele se encontra.

Figura 2 - Relação das três etapas da Teoria da Expectativa.
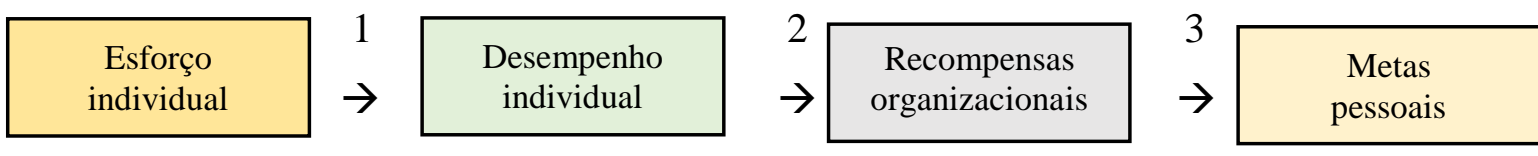

1 - Relação esforço - desempenho;

2 - Relação desempenho - recompensa;

3 - Relação recompensas - metas.

Outro ponto analisado neste estudo, foi as possibilidades de recompensas, -sem o intuito de esgotar as alternativas a serem aplicadas-, identificou-se na literatura algumas formas existentes, abordadas a seguir.

A remuneração, vista aqui como uma das formas possíveis de estímulo extrínseco, é o conjunto do salário e das recompensas financeiras que os funcionários recebem em troca da prestação de serviço (MILKOVICH; BOUDREAU, 2006). O tipo de remuneração poderá ser escolhido pela empresa, visando aquela que melhor atingirá os objetivos estabelecidos.

Segundo Alberto (2008) a remuneração é um componente que influencia na motivação dos indivíduos. Porém, quando não são isolados de outros fatores como: reconhecimento, autonomia, ambiente de trabalho, remuneração, flexibilidade no horário de trabalho. 
A remuneração quando é projetada e introduzida de maneira correta, poderá ocasionar o desempenho, a motivação, harmonização de interesses e um ótimo rendimento das pessoas e equipes na realização das atividades profissionais.

De acordo com Chiavenato (2004) recompensa é uma forma de estímulo concedida ao indivíduo através da execução de uma atividade, seja ela uma retribuição financeira ou não financeira. Nos conceitos clássicos, as pessoas eram motivadas somente por salários fixos, no qual era utilizado exclusivamente o tipo de remuneração funcional. Enquanto, a concepção contemporânea estabelece que os indivíduos podem ser motivados por outros tipos de recompensa, por isso as organizações podem atribuir várias formas de remunerar os colaboradores.

Nessa perspectiva, uma empresa para potencializar a motivação dos funcionários é fundamental possuir maleabilidade, pois os estímulos dos colaboradores atualmente são complexos, ou seja, variáveis. Será viável aderir vários tipos de remuneração, benefícios, flexibilidade no horário de trabalho, promoções, empowerment, trabalho à distância, entre outros (GRIFFIN, MOORHEAD, 2006).

Dentre as formas de recompensar, existem duas maneiras, a monetária e a nãomonetária: Recompensas monetárias: o dinheiro é uma fonte de motivação para os indivíduos, devido à necessidade dos bens materiais (alimentos, roupas, automóvel, residência). Isto é, através da moeda serão saciadas totalmente ou parcialmente as necessidades fisiológicas e de segurança da pirâmide de Maslow, além de ser um fator de estímulo para a realização das atividades profissionais, pois será através do empenho na execução do trabalho que será alcançado a remuneração (CHIAVENATO, 2014). Em contrapartida possui as recompensas não monetárias, que está relacionada com os aspectos que afetam a satisfação do indivíduo, mas que não são retribuídas por recursos financeiros, como no Quadro 1 pode ser visto exemplos dos tipos de recompensas (CHIAVENATO, 2014).

Quadro 1 - Distinção dos tipos de Recompensas.

\begin{tabular}{|c|c|}
\hline Recompensas monetárias & Recompensas não monetárias \\
\hline Salário & Qualidade de vida no trabalho \\
\hline Prêmios & Crescimento pessoal \\
\hline Benefícios & Reconhecimento \\
\hline
\end{tabular}




\begin{tabular}{|c|c|}
\hline Férias & Autorrealização \\
\hline $13^{\circ}$ salário & Flexibilidade no horário de trabalho \\
\hline
\end{tabular}

Os estudos já realizados discutem competências como Oliveira, Nascimento e Franco (2011) sobre a motivação no ambiente de trabalho, remuneração acionária, sentimento de propriedade e motivação dos empregados Godoi, Marcon, Balsini e Teixeira (2008) que tratou a motivação humana no trabalho, enfatizando os desafios da gestão em serviços de saúde pública, e o efeito da interdependência na satisfação de equipes de trabalho (PALACIOS E ANDRADE, 2005).

Diante do exposto, qual será o tipo de recompensa que mais motiva e estimula o colaborador a desempenhar e executar as atividades profissionais no ambiente de trabalho? Há relação entre o tipo de recompensa e o nível hierárquico?

Nesse sentido, o objetivo deste artigo foi investigar qual o tipo de recompensa que mais estimula e motiva os colaboradores no ambiente de trabalho e analisar se o tipo de recompensa independe do nível hierárquico. Avaliado através do estudo de caso aplicado na organização Unimed Vale do São Francisco - Operadora.

\section{Metodologia}

Para o alcance dos objetivos deste estudo, utilizou o tipo de pesquisa descritiva, e a técnica foi o estudo de caso. Segundo Bertucci (2012) a pesquisa descritiva relata e averigua o desenvolvimento do comportamento humano nas organizações através de diversas variáveis.

A unidade de análise foi a Cooperativa Unimed Vale do São Francisco- Operadora, localizada na cidade de Petrolina- PE, a organização está no mercado há 25 anos. Tem como atividade fim as questões administrativas da organização, possuindo no total 130 funcionários, subdividindo em quatro departamentos: Gestão de Pessoas, Controladoria, Administrativo e Comercial. A coleta de dados foi realizada entre os dias 06 e 10 de Outubro de 2016, os participantes da pesquisa encontram-se nos níveis hierárquicos tático e operacional. Eles foram 
escolhidos a partir de uma amostra aleatória, sorteados pelo software livre R versão 3.3.0, em que a quantidade sorteada foi adquirida através da fórmula: $\quad n=\frac{N \cdot \hat{p} \cdot \hat{q} \cdot\left(Z_{\alpha / 2}\right)^{2}}{\hat{p} \cdot \hat{q} \cdot\left(Z_{\alpha / 2}\right)^{2}+(N-1) \cdot E^{2}}$.

Onde:

$\mathrm{n}$ = Número de indivíduos na amostra;

$\mathrm{Z} \alpha / 2=$ Valor crítico que corresponde ao grau de confiança desejado;

$\mathrm{p}=$ Proporção populacional de indivíduos que pertence a categoria que estamos interessados em estudar;

$\mathrm{q}$ = Proporção populacional de indivíduos que não pertence à categoria que estamos interessados em estudar $(q=1-p)$;

$\mathrm{E}=$ Margem de erro ou erro máximo de estimativa. Identifica a diferença máxima entre a proporção amostral e a verdadeira proporção populacional (p).

Segundo Bruni (2011) a amostra aleatória simples é a forma de calcular a parte da população a ser realizado o estudo, em que os indivíduos possuem a mesma probabilidade de ser escolhidos. O tamanho da amostra foi de 55 colaboradores, contudo, foram sorteados 65 para que fossem substituídos caso ocorresse algum imprevisto no momento da pesquisa.

O instrumento de coleta de dados utilizado para a realização da pesquisa foi um formulário. Seguindo os preceitos de Marconi e Lakatos (2010) o formulário é desenvolvido através de perguntas executadas pelo entrevistador e preenchidas pelo mesmo através das afirmações recebidas pelo entrevistado. Neste formulário, havia somente duas alternativas de escolha para cada questão, com o objetivo de atribuir a mesma probabilidade para cada opção. Para verificar se havia diferença estatisticamente significativa entre o tipo de recompensa escolhido por todos os participantes foi utilizado o teste não paramétrico do qui- quadrado, através do software BioEstat 5.0. De acordo com Bruni (2011) o teste qui- quadrado explora a eventualidade nula para não surgir discordância entre as alternativas abordadas.

Em seguida, para alcançar o segundo objetivo, se a recompensa depende do nível hierárquico, também utilizou-se o teste não paramétrico do qui- quadrado no BioEstat 5.0.

As dimensões da pesquisa foram conduzidas com o objetivo de analisar qual das recompensas é mais relevante na motivação e satisfação para os colaboradores no ambiente de 
trabalho. Para isso, foram analisadas características individuais (sexo, idade, grau de escolaridade, cargo, nível hierárquico), como também, as variáveis recompensas monetárias e recompensas não monetárias. Com o intuito de verificar se as perguntas estavam de forma clara, foi realizado um teste piloto com duas pessoas da organização mencionada, que não foram selecionadas para a aquisição dos dados.

Os critérios utilizados na análise de dados foi aplicado de forma mista, isto é, o método quantitativo e o método qualitativo. A análise dos resultados tiveram como base a teoria da hierarquia das necessidades e a teoria da expectativa; apoado na teoria da hierarquia das necessidades para identificar o nível em que o colaborador da organização se encontra e a teoria da expectativa para distinguir qual o tipo de recompensa que levaria o funcionário a desempenhar cada vez melhor as atividades profissionais.

\section{Resultados e Discussão}

Participaram da pesquisa 55 colaboradores, no qual a idade mínima dos entrevistados foi de 19 anos e máxima de 57 anos. A média das idades dos funcionários foi de 32 anos e 9 meses, como mostra a Tabela 1. É possível perceber que, de acordo com o coeficiente de variação das idades, as idades são homogêneas, ou seja, não há grande disparidade nas idades dos participantes da pesquisa, como pode ser visto na Tabela 1.

Em relação ao tempo em que os funcionários trabalham na empresa, o tempo mínimo foi de 2 meses e o máximo de 20 anos, considerando que a organização está há 25 anos no mercado, constata-se que existem colaboradores que estão na empresa desde os primeiros anos. Como pode ser visto na Tabela 1, o coeficiente de variação do tempo de empresa, é bastante amplo.

Tabela 1 - Caracterização dos participantes da pesquisa.

\begin{tabular}{c|cccccc}
\hline Variáveis & Mínimo & Mediana & Máximo & Média & Desvio padrão & $\begin{array}{c}\text { Coeficiente } \\
\text { de Variação }\end{array}$ \\
\hline Idade & 19 anos & 31 anos & 57 anos & 32 anos e 9 meses & 9 anos e 6 meses & $28,97 \%$ \\
Tempo de Empresa & 2 meses & 2 anos e 6 meses & 20 anos & 4 anos e 6 meses & 5 anos e 1 mês & $113,14 \%$ \\
\hline
\end{tabular}


A primeira questão explorou qual das recompensas levaria a motivar o colaborador no ambiente de trabalho, 23 escolheram a opção relacionada à recompensa financeira (salário, benefícios, entre outros) e 32 escolheram a recompensa não financeira (reconhecimento, crescimento pessoal), de acordo com a Figura 3. No artigo referente à Motivação sem remuneração: um estudo de uma associação de estudantes de graduação da cidade de Santa Maria/RS, segundo Aguiar et al. (2012) foi observado nos resultados que todas as respostas que explanam a causa da motivação estão relacionadas as recompensas não financeiras, mas a mais relevante para os estudantes foi referente ao reconhecimento. Pode- se observar, através das duas pesquisas, que para um indivíduo manter- se motivado em uma organização é viável que o gestor reconheça o empenho do colaborador e que busque o crescimento pessoal do mesmo.

Este resultado pode ter ocorrido porque a Unimed Vale do São Francisco é uma organização que reconhece os funcionários dando a eles oportunidades de ascensão profissional, além de investir no crescimento pessoal. Ou seja, estes podem ser o conjunto de valores compartilhados pelos seus membros. Considerando a Teoria da Hierarquia das Necessidades e a escolha do tipo de recompensa que prevaleceu, subentende-se que alguns colaboradores da Unimed podem estar em um dos níveis mais alto da pirâmide. Em relação a Teoria da Expectativa, o gestor deve considerar a preferência do colaborador, pois, o funcionário poderá se esforçar mais se a organização investir em recompensas que estejam alinhadas com seu objetivo pessoal. No caso da organização analisada, para satisfazer o funcionário é adequado que a organização invista ainda mais no "reconhecimento" e crescimento pessoal dos seus colaboradores, do que investir em recompensas extrínsecas.

No segundo quesito, foi indagado se o funcionário aceitaria a mudança de cargo, ou seja, o aumento de responsabilidades, além de estender o tempo de trabalho com o objetivo de aumentar o salário, 31 optaram pela recompensa financeira e 24 pela recompensa não financeira, de acordo com a Figura 3.

Sob a perspectiva do estudo Lima, Machado e Estender (2015) o plano de carreira e plano de remuneração para motivação e retenção de talentos, segundo eles o plano de carreira e de remuneração são meios de buscar a motivação do colaborador, pois com o plano de carreira o funcionário poderá ter uma visão mais ampla para o desenvolvimento profissional, além do plano de remuneração, que irá agregar um valor ao salário pelo desempenho individual. Porém, 
realizando uma analogia com o cenário abordado nesta questão com a teoria da hierarquia das necessidades, pode- se observar que os funcionários estão em hierarquias de necessidades diferentes, alguns preferem os recursos financeiros (recompensa financeira), outros preferem menos responsabilidade e menos esforço (recompensa não financeira).

Em relação à pergunta que menciona se o colaborador trocaria a empresa em que trabalha atualmente por outra que proporcionaria um salário acima da média do mercado, 18 escolheram a recompensa financeira e 37 a não financeira, conforme mostra a Figura 3. Foi observado que a maioria que optou por a recompensa não financeira, para eles o dinheiro não é o mais relevante, e que preferiam permanecer na empresa atual. De acordo com Silva (2013) baseando- se na teoria da hierarquia das necessidades de Abraham Maslow, os colaboradores que fundamentaram uma resposta para a escolha da recompensa não financeira possivelmente alcançaram a segunda etapa da pirâmide (necessidades de segurança), pois conforme a justificativa foi subentendida que os mesmos sentem- se seguros no emprego atual. Como também, relacionando com a Teoria da Expectativa pode ser observado que as metas pessoais dos funcionários estão associadas com as recompensas não financeiras, isto é para os colaboradores se esforçarem e dar o melhor de si, é preciso que as recompensas organizacionais sejam equivalentes aos interesses dos empregados. Logo, os funcionários preferem a segurança no emprego atual a salário acima da média do mercado.

Quanto à situação que alude se o funcionário substituiria o recebimento da recompensa não financeira pela recompensa financeira, 39 optaram por a recompensa financeira e 16 por a não financeira, segundo a ilustração da Figura 3. Segundo a Teoria da Hierarquia das Necessidades, a escolha da recompensa está relacionada com o nível da hierarquia no qual o indivíduo se encontra, pois, a escolha é para satisfazer a necessidade ou a carência individualizada.

A respeito da oportunidade de emprego na organização em que o colaborador sempre desejou trabalhar, mas que a vaga disponível seria em um departamento em que o mesmo não possui afinidade, qual seria o principal motivo relacionado às recompensas que levaria o indivíduo a aceitar o ensejo, 18 escolheram a recompensa financeira e 37 a não financeira, como demonstrado na Figura 3. De acordo com o estudo, a motivação humana no trabalho: o desafio da gestão em serviços de saúde pública, realizado pelos autores Lopes e Regis Filho (2004) os fatores que estão associados a motivação/satisfação são as condições de trabalho, a tarefa em 
si, relações interpessoais, pode- se observar que os dois estudos possuíram o mesmo tipo de recompensa para motivar os funcionários das duas organizações estudadas. Conforme analisado em outra pesquisa, realizada pelo autor Alberto (2008), pôde- se observar que vários fatores geram a satisfação do colaborador, sendo eles: remuneração, autonomia, reconhecimento, oportunidade de crescimento, ambiente de trabalho, entre outros. Relacionando os resultados das pesquisas exploradas com a Teoria da Hierarquia das Necessidades foi analisado que não há uma recompensa universal para os indivíduos, isto é, o fator que gera a motivação está vinculado com a hierarquia das necessidades de cada pessoa. Seguindo os conceitos da teoria da expectativa, será através das recompensas recebidas que o indivíduo determinará qual a organização irá buscar uma oportunidade de trabalho, como também, buscar o esforço para alcançar um bom desempenho no emprego (SILVA, 2013).

Quanto à participação dos colaboradores na produção de uma política de redução de custos, prevaleceu a escolha da recompensa financeira, no qual 30 funcionários desejariam à financeira e 25 a recompensa não financeira, como é identificado na Figura 3.

Em relação ao quesito que tratou sobre a possibilidade de a empresa presentear o colaborador no dia do aniversário com um tipo de recompensa, 29 funcionários escolheram a recompensa financeira e 26 a não financeira, conforme Figura 3. De acordo com Maximiano (2011) as pessoas são similares e distintas concomitantemente, ou seja, os indivíduos possuem necessidades em comum, mas em cada circunstância diferente. Como pode ser analisado, houve uma diferença mínima nas escolhas das recompensas. Conforme a Teoria da Hierarquia das Necessidades, a escolha do tipo de recompensa dependerá da hierarquia da necessidade em que o colaborador se encontra. Como também, relacionando com a Teoria da Expectativa, o funcionário só sentirá motivado e satisfeito com o presente recebido, se o brinde estiver relacionado com a sua necessidade.

A partir da análise dos resultados, é possível constatar que os gestores, -para atingir o desempenho satisfatório do funcionário-, precisa ficar atento ao que os motiva de forma individualizada. Através desta pesquisa observou-se que alguns indivíduos com níveis hierárquicos diferentes, escolheram a mesma opção de recompensa, como também, pessoas com o mesmo nível hierárquico elegeram alternativas diferentes, ou seja, as pessoas possuem expectativas/objetivos diferentes. Salientando também que, conforme a teoria de Abraham 
Maslow, cada indivíduo está em um nível da hierarquia de necessidades, no qual pode ser distinto de outro indivíduo, no caso da empresa analisada, este nível independe do cargo.

Figura 3 - Quantificação dos questionamentos - Teste Qui quadrado.

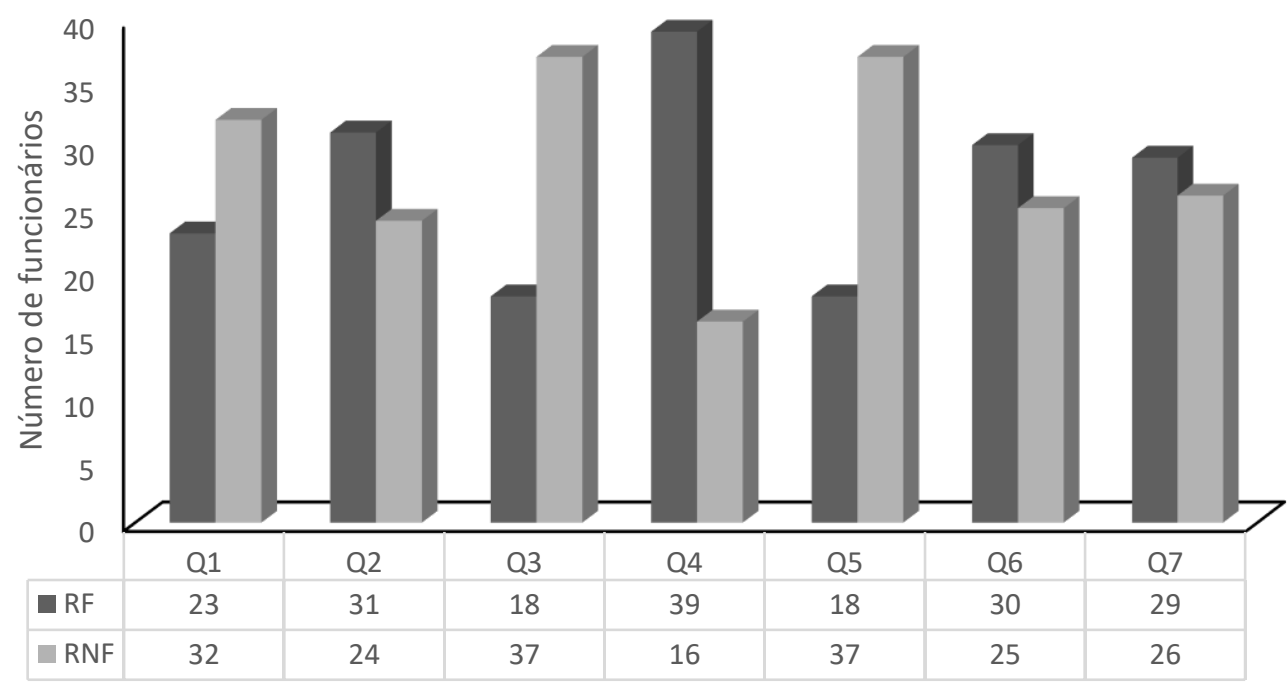

$\mathrm{RNF}=$ Recompensa não financeira; $\mathrm{RF}=$ Recompensa financeira.

De acordo com o teste Qui- quadrado foi demonstrado que nesta pesquisa a hipótese é não significativa para todas as situações abordadas nas sete questões, isto é, a escolha das recompensas independe do nível hierárquico no qual o colaborador se encontra, como pode ser visto na Tabela 2.

Tabela 2 - Exploração dos aspectos da amostra, fragmentação dos níveis hierárquicos.

Q1- Qual destas opções te levaria realmente a se motivar em uma organização?

Q2 - Surge uma vaga para um cargo em um nível hierárquico superior ao qual você se encontra hoje na organização e o colaborador selecionado para as devidas mudanças de cargos foi você. Você estaria disposto (a) a aumentar as suas responsabilidades, demandar mais esforço, ampliar seu tempo de trabalho para a execução de atividades profissionais no intuito de aumentar seu salário, benefícios, isto é, acrescer seu aspecto financeiro? Q3 - Você trabalha em uma empresa que oferece crescimento pessoal, flexibilidade no horário de trabalho e reconhecimento dos superiores. Porém, uma outra organização te convida para fazer parte do quadro de

$\begin{array}{cc}\text { Estatística } & \text { P-Valor } \\ \text { Qui-quadrado } & \\ 1,3911 & 0,2382 \\ 0,6029 & 0,4375\end{array}$

0,0152

0,902 
funcionários e te proporciona um salário acima da média do mercado. Você aceitaria a proposta de mudança ou continuaria na empresa atual?

Q4 - Considere que a organização que você trabalha oferece mais desenvolvimento) do que recompensas financeiras (plano de saúde, ticket de alimentação, salário). Contudo, os diretores estão analisando a possibilidade de inverter esse quadro, e essa decisão será tomada com todos os colaboradores, visando escolher aquela que mais poderá trazer a motivação no ambiente de trabalho. Você estaria disposto (a) a trocar a recompensa não financeira por a recompensa financeira?

Q5 - Surge uma vaga em uma organização em que você sempre desejou trabalhar devido a imagem que a mesma possui no mercado e a forma de como reconhece o seu colaborador. Porém, a vaga disponível é no departamento em que você não possui afinidade. Qual destas opções te levaria a escolher a entrar na empresa mesmo não sendo no setor desejável? Q6 - Em tempos de crise, a Diretoria decide desenvolver uma nova política com o objetivo de reduzir custos. Com isso, será necessário a participação dos colaboradores na criação dessa nova política para ser atingido o objetivo requisitado. Caso você consiga o propósito estabelecido, para você qual seria a forma ideal a ser recompensado (a)?

Q7 - No dia do seu aniversário a empresa gostaria de te presentear com um tipo de recompensa. Qual destas você desejaria receber?

$\mathrm{X} 2=\mathrm{P} \leq 0,05(\mathrm{RNF}=$ Recompensa não financeira; $\mathrm{RF}=$ Recompensa financeira; $\mathrm{p}=$ resultados estatisticamente não significativos) - Teste não paramétrico do qui-quadrado.

Pode ser observado que o P- valor em todas as questões foram maiores que 0,05 , logo, demonstram que os resultados estaticamente são não significativos, ou seja, as variáveis estudadas (tipo de recompensa X nível hierárquico) são independentes.

\section{Considerações Finais}

Diante da elevada competitividade, o administrador, para alcançar os objetivos organizacionais, não pode mais gerir por tentativa e erro. Ele deve compreender quais são os objetivos pessoais do funcionário, com o intuito de melhor estimulá-lo a aumentar seus esforços, pois, seu engajamento é determinante para permanência e crescimento da empresa.

O objetivo deste artigo foi descrever qual o tipo de recompensa que levaria o funcionário a se sentir motivado, e, se a escolha da recompensa possuía relação com o nível hierárquico. Foi desenvolvida uma pesquisa descritiva com o intuito de observar a percepção dos 
colaboradores. Através do estudo realizado na empresa Unimed Vale do São FranciscoOperadora, constatou-se que o tipo de recompensa que motiva o colaborador não está relacionado com o nível hierárquico no qual se encontra. Além de existir várias maneiras de motivar um funcionário, podendo a escolha da recompensa ser influenciada pela necessidade em que o indivíduo encontra- se no momento.

Diante de alguns estudos Marcelino (2015) realizados anteriormente por outros autores, foi identificado que os colaboradores de outras empresas também consideram a recompensa financeira um fator motivador, seja ele um salário íntegro, vale alimentação, vale transporte, entre outros. Ainda investigando outros resultados, Lopes e Regis Filho (2004), foi apontado que as pessoas preferem um cargo com maior responsabilidade com o intuito de aumentar a remuneração e se empenhar ainda mais para buscar um crescimento profissional dentro da organização. No qual, avaliando os resultados das pesquisas foi apresentado divergência, em que foi visto que as pessoas buscam para trabalhar, empresas que oferecem melhores condições de recompensas financeiras, já nesta pesquisa foi identificado individualmente na questão cinco, que o indivíduo aceitaria a trabalhar na empresa mesmo não sendo no departamento que possui afinidade pela recompensa não financeira.

Por isso, recomenda-se que quando a organização possuir o objetivo de motivar o colaborador, seja levado em consideração todas as possibilidades, e principalmente, alinhar com as metas pessoais dos colaboradores. Disponibilizar qualidade nas questões relacionadas às atividades profissionais, como condições físicas e psicológicas de trabalho, e também remunerar o colaborador de forma justa, em que o salário corresponda às atividades atribuídas, como também, seja equivalente ao mercado. Estreitar o relacionamento do funcionário com a organização, dando a ele a oportunidade de participar consideravelmente do sucesso da empresa, como já foi dito, os funcionários são a peça chave da organização, pois são eles que irão executar as tarefas designadas e saberão quais são as melhores formas de realizá-las.

Com relação as limitações da pesquisa, observou-se a quantidade de questões realizadas para a criação do formulário. Tendo em vista que todas as questões tinham que estar relacionadas com os tipos de recompensa financeira e não financeira, além de estarem associadas as duas teorias motivacionais, a Teoria da Hierarquia das Necessidades e a Teoria da Expectativa. 
Sugere-se a realização de novas pesquisas para avaliar qual o tipo de recompensa gera motivação aos colaboradores alinhada com outras teorias motivacionais, e também estudos mais abrangentes de modo que os resultados possam ser generalizados. Haja vista que os resultados alcançados nesta pesquisa representam as preferências dos colaboradores da Unimed Vale do São Francisco- Operadora.

\section{Referências}

AGUIAR, V. L et al. Motivação sem remuneração: um estudo de uma associação de estudantes de graduação da cidade de Santa Maria/RS. Simpósio de Excelência em Gestão e Tecnologia, Rio de Janeiro, p. 2-10, 2014.

ALBERTO, D. G. O alinhamento das âncoras de carreira: explorando a satisfação com o trabalho. 2008. 97 f. Dissertação (Mestrado em Administração) - Pontifícia Universidade Católica de São Paulo, SP, 2008.

BERTUCCI, J. L. O. Metodologia básica para elaboração de trabalhos de conclusão de cursos (TCC): ênfase na elaboração de TCC de pós-graduação Lato Sensu. São Paulo: Atlas, 2012.

BIRCK, Karin; GOMES, Luciane da Silva. Endomarketing: como diferencial competitivo. Contribuciones a la Economía, Málaga/Esp., mayo, 2013. Disponível em: <www.eumed.net/ce/2013/endomarketing.html>. Acesso em: 18 jan. 2017.

BRUNI, A. L. Estatística aplicada à gestão empresarial. São Paulo: Atlas s.a, 2011.

CHIAVENATO, I. Administração: teoria, processo e prática. Barueri: Manole, 2014.

CHIAVENATO, I. Comportamento organizacional: a dinâmica do sucesso das organizações. Barueri: Manole, 2014.

CHIAVENATO, I. Gestão de pessoas: e o novo papel dos recursos humanos nas organizações. Rio de Janeiro: Elsevier, 2004.

GRIFFIN, R.W; MOORHEAD, G. Fundamentos do comportamento organizacional. São Paulo: Ática, 2006.

JONES, G.R; GEORGE, J.M. Administração contemporânea. São Paulo: McGraw- Hill, 2008. 
LIMA, G. M.; MACHADO, D.; ESTENDER, A. C. Plano de carreira e plano de remuneração para motivação e retenção de talentos. In/: SIMPÓSIO DE EXCELÊNCIA EM GESTÃO E TECNOLOGIA. Anais eletrônicos...: gestão de pessoas. Rio de Janeiro, 2015.

LOPES, M. C; REGIS FILHO, G. I. A motivação humana no trabalho: o desafio da gestão em serviços de saúde pública. R.Adm, v. 39, n. 1, p. 62-75, 2004.

MARCELINO, A. F. Sistema de remuneração: estudo em uma empresa desenvolvedora de software. ReCaPe Revista de Carreiras e Pessoas, v. 5, n. 2, 2015.

MARCONI, M. A.; LAKATOS, E. M. Fundamentos de metodologia científica. São Paulo: Atlas, 2010.

MAXIMIANO, A. C. A. Introdução à administração. São Paulo: Atlas, 2011.

MILKOVICH, G.T; BOUDREAU, J.W. Administração de recursos humanos. São Paulo: Atlas, 2006.

ROBBINS, S. P.; JUDGE, T. A.; SOBRAL, F. Comportamento organizacional: teoria e prática no contexto brasileiro. São Paulo: Pearson Prentice Hall, 2010.

SILVA, R. O. Teorias da administração. São Paulo: Pearson Education do Brasil, 2013.

WAGNER, J. A.; HOLLENBECK, J. R. Comportamento organizacional: criando vantagem competitiva. São Paulo: Saraiva, 2012

\section{Como citar este artigo (Formato ABNT):}

ALVES, Larissa C.; SILVA, Adriano V.L.; OLIVEIRA, Érika M.J. Motivação e Recompensas: uma investigação com base nas Teorias da Hierarquia das Necessidades e da Expectativa. Id on Line Revista Multidisciplinar e de Psicologia, Maio de 2017, vol.11, n.35, p. 325-340. ISSN: 1981-1179.

Recebido: 23.04.2017

Aceito: 26.05.2017 